ISSN 0103-5150

Fisioter. Mov., Curitiba, v. 30, n. 2, p. 391-398, Apr./June 2017

Licenciado sob uma Licença Creative Commons

DOI: http://dx.doi.org/10.1590/1980-5918.030.002.AR02

\title{
Effects of strength training on the treatment of patellofemoral pain syndrome - a meta-analysis of randomized controlled trials
}

\author{
Efeitos do treinamento de força no tratamento da síndrome da dor \\ femoropatelar - uma metanálise de ensaios clínicos randomizados
}

\author{
Rodrigo Kohn Cardoso, Eduardo Lucia Caputo, Airton José Rombaldi, Fabrício Boscolo Del Vecchio*
}

Universidade Federal de Pelotas (UFPEL), Pelotas, RS, Brazil

\begin{abstract}
Introduction: Palletofemoral pain syndrome (PFPS) is anterior knee pain that affects around $25 \%$ of the population at some point in their lives. Muscle weakness is one of the main causal factors related to PFPS. Objective: Conduct a quantitative analysis on the effectiveness of strength training at reducing pain in PFPS sufferers. Methods: An electronic search was conducted on the MEDLINE, Pubmed, EMBASE, Lilacs and Scielo databases for studies published between January 2005 and September 2014. The following descriptors were used: "patellofemoral pain syndrome", "patellofemoral pain", "retropatellar pain", "exercise", "exercise therapy", "strength", "rehabilitation". Only randomized controlled trials (RCTs) that compared the effects of strength training to no exercise in terms of reducing pain among PFPS sufferers were included. Data were extracted by two independent authors using predefined quality indicators. Results: A total of 39 RCTs were initially identified in the search. However, only five met the inclusion criteria. Strength training exhibited a positive effect on PFPS (SMD = 0.85, CI: 0.45-1.25). However, high heterogeneity was observed between the studies $\left(\mathrm{p}<0.05 ; \mathrm{I}^{2}=68.3 \%\right)$. Conclusion: Strength training showed a statistically positive response in the treatment of PFPS.
\end{abstract}

Keywords: Knee. Strength Training. Patella.

\footnotetext{
* RKC: MS, e-mail: rodrigokohn21@yahoo.com.br

ELC: Doctoral Student, e-mail: caputoeduardo@yahoo.com.br

AJR: PhD, e-mail: rombaldi@brturbo.com.br

FBDV: PhD, e-mail: fabricio_boscolo@uol.com.br
} 
Resumo

Introdução: A síndrome da dor femoropatelar (SDF) é uma patologia da região anterior do joelho que atinge cerca de $25 \%$ da população em algum momento da vida. Dentre os fatores causais relacionados com a SDF, destaca-se o enfraquecimento muscular. Objetivo: Realizar uma análise quantitativa da eficácia do exercício de força na redução da dor em portadores de SDF. Métodos: Foi realizada uma busca eletrônica nas bases de dados MEDLINE, Pubmed, EMBASE, Lilacs e Scielo, limitada entre o período de janeiro de 2005 e setembro de 2014. Os seguintes descritores foram usados, em língua inglesa: "patellofemoral pain syndrome", "patellofemoral pain", "retropatellar pain", "exercise", "exercise therapy", "strength", "rehabilitation". Apenas ensaios clínicos randomizados que comparassem os efeitos do treinamento de força ao não exercício na redução da dor de portadores de SDF foram incluídos. A extração de dados foi realizada por dois autores de forma independente, utilizando indicadores de qualidade pré-definidos. Resultados: Total de 39 ECR's foi identificado inicialmente na pesquisa. No entanto, apenas cinco estudos contemplaram os critérios de inclusão. O treinamento de força apresentou efeito positivo sobre a SDF $(S M D=0,85, I C: 0,45-1,25)$. Contudo, foi encontrada alta heterogeneidade entre os estudos $(p<0,05 ; 12=68,3 \%)$.

Conclusão: Evidenciou-se resposta estatisticamente positiva do treinamento de força no tratamento da SDF.

Palavras-chave: Joelho. Treinamento de Resistência. Patela.

\section{Introduction}

Palletofemoral pain syndrome (PFPS), characterized by anterior knee pain with no definitive cause or diagnosis (1), can be defined as pain around the kneecap (patella) resulting from physical and biomechanical changes in this joint (2). Other commonly used terms include anterior knee pain, chondromalacia patella, palletofemoral arthralgia and palletofemoral pain (3). The condition can be exacerbated by activities such as going up and down stairs, sitting for prolonged periods, running and squatting (4).

PFPS affects around $7 \%$ of active young adults and about $25 \%$ of people at some stage in their lives, but is most common among the former (5). Incidence rates are even more pronounced among sports enthusiasts, accounting for up to $40 \%$ of injuries in sports medicine (6).

Dye et al. (7) suggested that the onset of PFPS is likely the result of a complex pathophysiological process, which may include peripatellar synovitis, increased pressure and internal bone remodeling.

Despite the lack of consensus on the causes of this condition, several factors are believed to contribute to its development, such as weakness in the quadriceps (8), changes in the posture alignment of the lower limbs (9), abnormal leg biomechanics, (10), smaller knee flexion angle (11), weak hip muscles (12), excessive adduction and internal rotation of the hip (13) and, primarily, kneecap misalignment (8).

The treatment of PFPS is still a challenge in the scientific literature. There is no standard recommended treatment, although it is believed that conservative non-surgical approaches produce good results, with a resolution rate of up to $87 \%$ (5). Conventional treatment generally includes physiotherapy (14), strengthening the quadriceps, using a knee brace and taping, as well as soft tissue mobilization and stretching $(15,16)$. In this respect, muscle strengthening aims to combat neuromuscular deficits, which include the quadriceps, vastus medialis oblique muscle, proximal muscle strength deficits, soft tissue tightness or abnormal knee alignment (17). A variety of exercises are used in different combinations, including open and closed kinetic chain exercises and stretching (18).

In a study of PFPS sufferers, van Linschoten et al. (19) concluded that exercise improves pain and functionality in the knee joint in the short and long term. Similar results were found by Song et al. (20), who observed an improvement in these parameters regardless of the resistance exercise used. As such, the primary aim of this study was to conduct a quantitative analysis of the effectiveness of strength training at reducing pain in PFPS sufferers. 


\section{Methods}

\section{Search strategysong}

In the literature review, only randomized controlled trials (RCTs) that aimed to assess the effectiveness of strength training in PFPS treatment were selected. An electronic search was conducted on the MEDLINE, Pubmed, EMBASE, Lilacs and Scielo databases for studies published between January 2005 and September 2014.

The descriptors used during the review process were chosen after consulting Medical Subject Headings (MeSH), as follows: "patellofemoral pain syndrome", "patellofemoral pain", "retropatellar pain", "exercise", "exercise therapy", "strength", "rehabilitation". The Boolean operators "AND" and "OR" were used to combine the search terms.

Study eligibility and selection criteria

Studies included were RCTs; articles published in English or Portuguese; papers that measured the variable "pain"; and those that provided means and their respective standard deviations on a pain scale for each group. Abstracts and studies whose sample contained only adolescents were not included.

Based on the PRISMA diagram (Preferred Reporting Items for Systematic Reviews and MetaAnalysis) (21), two authors independently evaluated the methodological quality of all the selected studies. Disagreements between the authors were resolved by consulting a third reviewer. The decision to include or exclude studies was initially made by analyzing its title, followed by the abstract and, finally, the entire manuscript. The flow chart considered 52 studies at the start of the search and finished with five (Figure I).

\section{Data Collection}

Information was extracted from each study based on: 1) population - characteristics of study participants - age and diagnostic method; 2) intervention characteristics of the intervention protocol - duration, frequency, intensity, volume and types of exercises, compared to a control group, and; 3) result - type of outcome measured - pain intensity.

\section{Statistical analysis}

Data were analyzed using the Stata 12.1 program. Cochran's Q test was applied to evaluate inter-study heterogeneity. The level of inconsistency between the trials was estimated using the $I^{2}$ statistic, where an $I^{2}$ value close to $75 \%$ indicates high heterogeneity, according to Higgins et al. (22).

As suggested by DerSimonian \& Laird (23), the primary outcome of the studies (pain) was pooled using a random effects model.

\section{Results}

A total of 39 RCTs were initially identified in the search. Of these, 25 were considered for assessment based on their titles. Four were excluded as duplicates, leaving 21 studies eligible for analysis of the full text. A total of five studies met all the selection criteria (Figure 1).

Most of the studies used the visual analog scale (VAS) to measure pain intensity, while only one (24) used the Numerical Pain Rating Scale (NPRS). Two studies included only women $(24,25)$ and two investigated adolescents $(19,26)$. Since two of the studies contained three groups $(20,24)$, two of which performed exercises, the five articles reported a total of seven results, given that these were included in the meta-analysis twice, with each intervention compared to the control. Table I shows the five studies on physical exercise and PFPS included in the meta-analysis.

Five articles (377 participants) analyzed the effect of strength training (219 participants) compared to a control group (158 participants) on PFPS (19, $20,24,25,26)$. Five of the seven results included in the meta-analysis exhibited a significant difference in relation to the baseline, indicating a positive effect on PFPS ( $p<0.001)$ (Figure 2). However, the results demonstrated high heterogeneity $(\mathrm{p}<0.05$; $I^{2}=68.3 \%$ ), but within the tolerance limit. 

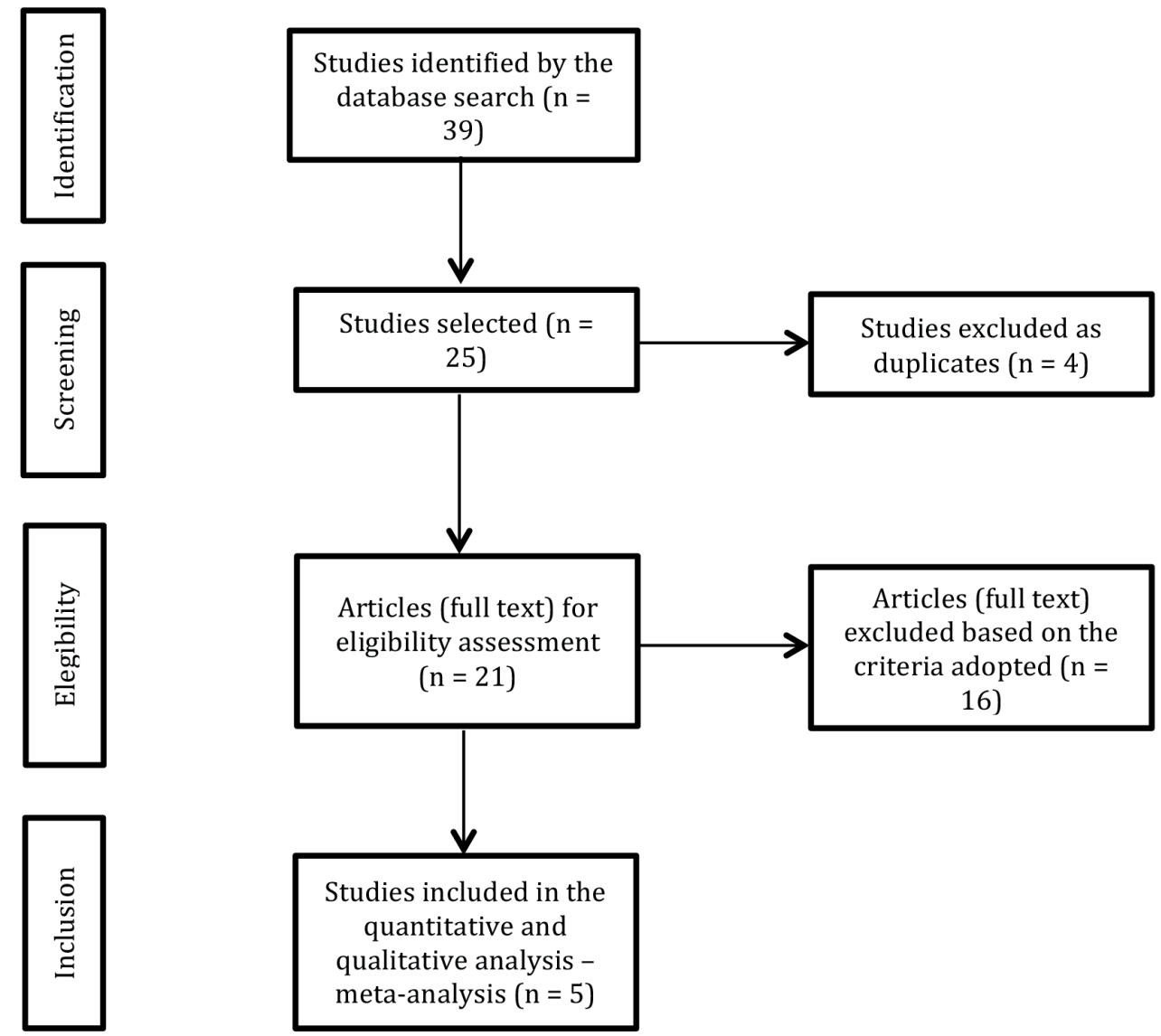

Figure 1 - Flow chart of the search process

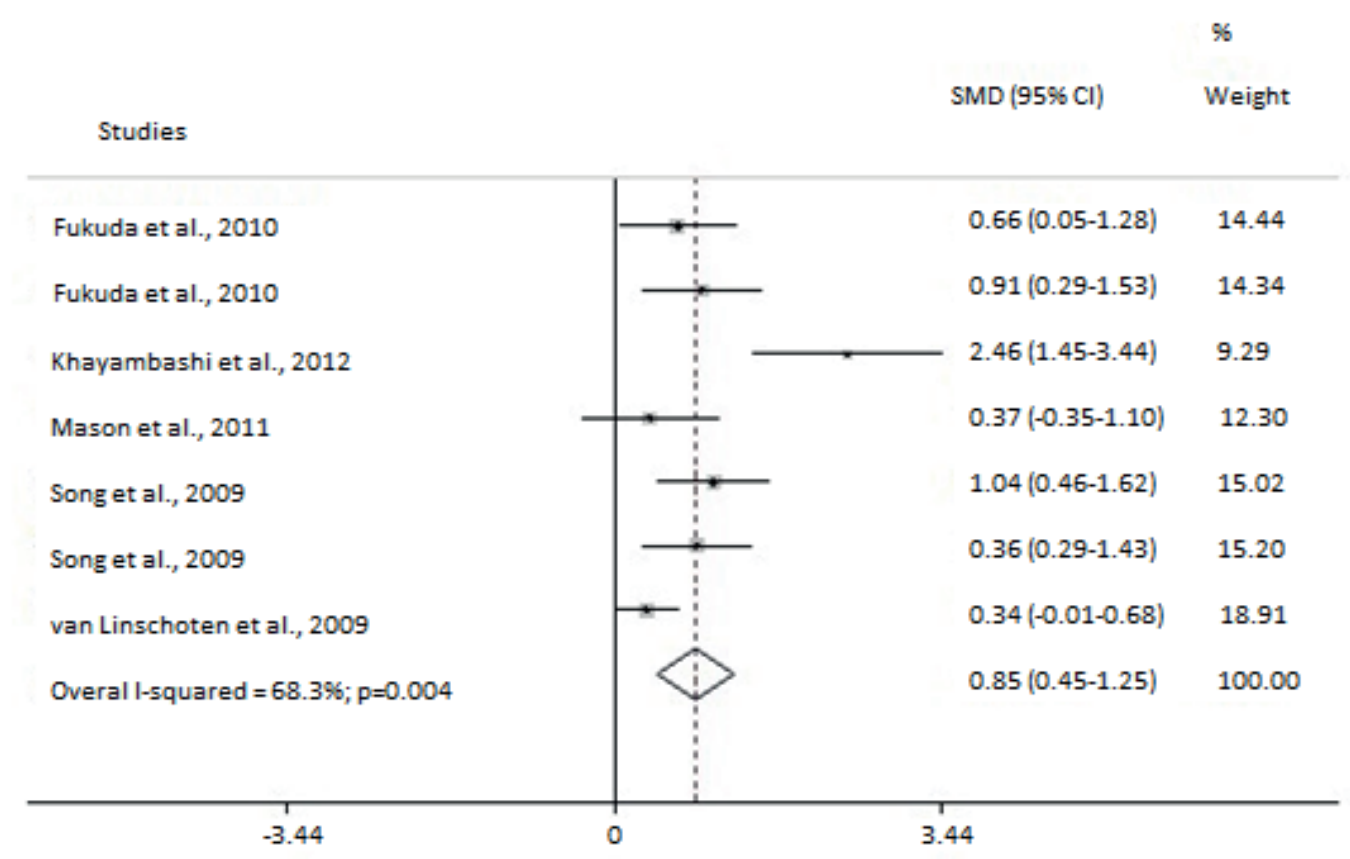

Figure 2 - Forest plot of the effect of exercise on PFPS 


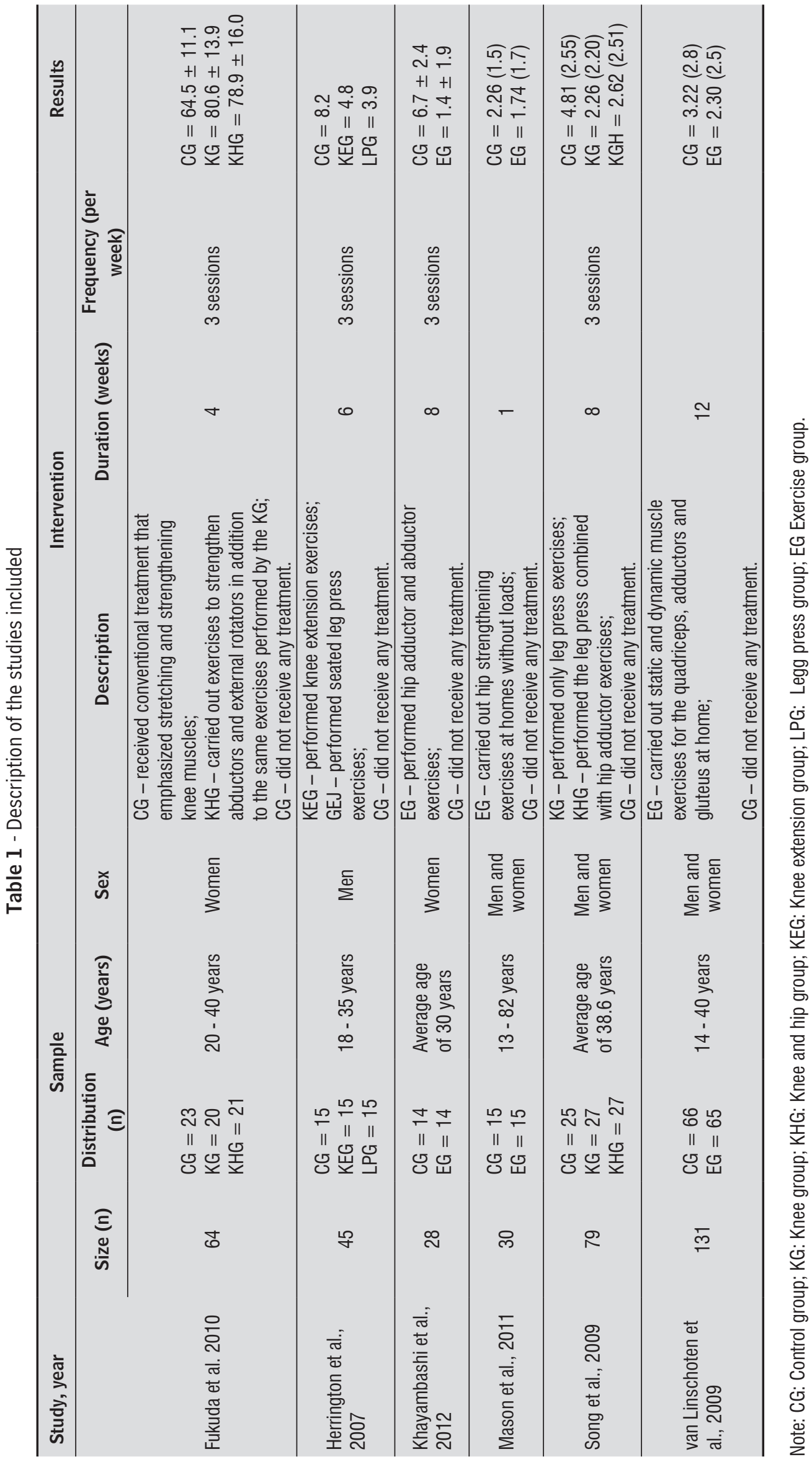




\section{Discussion}

Our study aimed to assess the effectiveness of strength training on PFPS treatment and the overall result indicated a positive effect for this type of intervention on the outcome studied. Despite the lack of meta-analyses on this subject, literature reviews on the issue corroborate the findings of the present study $(16,27,28)$.

Strength training is effective in the treatment of PFPS. Previous research demonstrates the importance of strengthening hip adductor muscles and lateral rotators, as well as the quadriceps, since these also exhibit weakness, particularly in women with the condition $(29,30)$. The weakening of these muscles can trigger internal rotation or adduction of the hip, causing an increase in the quadriceps (Q) angle formed by the intersection of two imaginary lines, one from the ASIS (anterior superior iliac spine) to the central patella and the other from the tibial tubercle to the central patella. This increased Q angle leads to patella subluxation, which intensifies the patellofemoral peak pressure, one of the causes of PFPS $(31,32,33)$. In addition, weakness in these muscles may cause patellar facet overload $(13,34)$.

Recent evidence indicates that increased strength and better hip flexibility have become essential in treating PFPS (35). This factor is justified in that adequate dynamic control of the pelvis helps patients improve the mechanics of the patellofemoral joint (15).

In addition to demonstrating the importance of improving the strength and flexibility of hip muscles $(20,24)$, the studies included in this meta-analysis largely applied intervention protocols targeting the quadriceps, using both open and closed kinetic chain exercises $(19,25,26,34,36)$. Mason et al. (26) studied the effect of hip strengthening exercises on PFPS treatment and concluded that this type of intervention is effective in reducing pain and improving functional capacity. This clearly demonstrates the effectiveness of strengthening the anterior thigh muscles, particularly the vastus medialis, in terms of reducing pain in PFPS sufferers, which corroborates the findings of Harvie et al. in their literature review on the theme (34).

Our results exhibited high heterogeneity (68.3\%). This finding can be attributed to the fact that the effect of the exercise reported by Khayambashi et al. (25) was far greater than that observed in the other studies included in the meta-analysis.

\section{Conclusion}

The main outcome of this investigation suggests a positive effect of strength training on PFPS treatment. From a clinical perspective, these findings indicate the importance of muscle strengthening, especially the anterior thigh muscles, in the treatment of PFPS.

\section{References}

1. Crossley KM, Cowan SM, Bennell KL, McConnell J. Knee flexion during stair ambulation is altered in individuals with patellofemoral pain. J Orthop Res. 2004;22(2):267-74.

2. Nobre TL. Comparação dos exercícios em cadeia cinética aberta e cadeia cinética fechada na reabilitação da disfunção femoropatelar. Fisioter Mov. 2011;24(1):167-72. Portuguese.

3. Thomee R, Augustsson J, Karlsson J. Patellofemoral pain syndrome, a review of current issues. Sports Med. 1999;28(4):245-62.

4. McConnell J. What are effective therapies for anterior knee pain. In: Wright JG, editor. Evidence Based Orthopaedics: The Best Answers To Clinical Questions. Philadelphia (PA): Saunders Elsevier Inc; 2009. p. 634-9.

5. van Linschoten $\mathrm{R}$, van Middelkoop $\mathrm{M}$, Berger MY, Heintjes EM, Verhaar JA, Willemsen SP, et al. Supervised exercise therapy versus usual care for patellofemoral pain syndrome: an open label randomised controlled trial. BMJ. 2009;339:b4074.

6. Bizzini M, Childs JD, Piva SR, Delitto A. Systematic Review of the Quality of Randomized Controlled Trials for Patellofemoral Pain Syndrome. J Orthop Sports Phys Ther. 2003;33(1):4-20.

7. Dye S, Saubli HU, Biedert RM, Vaupel GL. The mosaic of pathophysiology causing patellofemoral pain: therapeutic implications. Oper Tech Sports Med. 1999;7(2):46-54.

8. Thijs Y, Tiggelen D, Roosen P, Clercq D, Witvrouw E. A prospective study on gait-related intrinsic risk factors for patellofemoral pain. Clin J Sport Med. 2007;17(6):437-45. 
9. Belchior ACG, Arakaki JC, Bevilaqua-Grossi D, Reis FA, Carvalho PTC. Efeitos na medida do ângulo Q com a contração isométrica voluntária máxima do músculo quadricipital. Rev Bras Med Esporte. 2006;12(1):6-10.

10. Levinger P, Gilleard W. An evaluation of the rearfoot posture in individuals with patellofemoral pain syndrome. J Sports Sci Med. 2004;3(1):8-14.

11. Brechter J, Powers C. Patellofemoral joint stress during stair ascent and descent in persons with and without patellofemoral pain. Gait Posture. 2002;16(2):115-23.

12. Bolgla L, Malone T, Umberger B, Uhl T. Comparison of hip and knee strength and neuromuscular activity in subjects with and without patellofemoral pain syndrome. Int J Sports Phys Ther. 2011;6(4):285-96.

13. Powers $\mathrm{C}$. The influence of altered lower extremity kinematics on patellofemoral joint dysfunction: a theoretical perspective. J Orthop Sports Phys Ther. 2003;33(11):639-46.

14. American Physical Therapy Association. Guide to Physical Therapist Practice. 2nd ed. Alexandria (VA): American Physical Therapy Association; 2003.

15. Tyler TF, Nicholas SJ, Mullaney MJ, McHugh MP. The role of hip muscle function in the treatment of patellofemoral pain syndrome. Am J Sports Med. 2006;34(4):630-6.

16. Post W. Patellofemoral pain: results of nonoperative treatment. Clin Orthop Relat Res. 2005;(436):55-9.

17. Mascal Cl, Landel R, Powers C. Management of patellofemoral pain targeting hip, pelvis, and trunk muscle function: 2 case reports. J Orthop Sports Phys Ther. 2003;33(11):647-60.

18. Fagan V, Delahunt E. Patellofemoral pain syndrome: a review on the associated neuromuscular deficits and current treatment options. Br J Sports Med. 2008;42(10):789-95.

19. van Linschoten R. Patellofemoral Pain Syndrome and Exercise Therapy [disseratation]. Rotterdam (The Netherlands): Erasmus Universiteit Rotterdam; 2012.

20. Song CY, Lin YF, Wei TC, Lin DH, Yen TY, Jan MH. Surplus value of hip adduction in leg-press exercise in patients with patellofemoral pain syndrome: a randomized controlled trial. Phys Ther. 2009;89(5):409-18.
21. Liberati A, Altman DG, Tetzlaff J, Murlow C, Gøtzsche PC, Ioannidis JP, et al. The PRISMA statement for reporting systematic reviews and meta-analyses of studies that evaluate healthcare interventions: explanation and elaboration. BMJ. 2009;339:b2700.

22. Higgins JP, Thompson SG, Deeks JJ, Altman DG. Measuring inconsistency in meta-analyses. BMJ. 2003;327(7414):557-60.

23. DerSimonian R, Laird N. Meta-analysis in clinical trials. Control Clin Trials. 1986;7(3):177-88.

24. Fukuda TY, Rossetto FM, Magalhães E, Bryk FF, Lucareli PR, Almeida ACN. Short-term effects of hip abductors and lateral rotators strengthening in females with patellofemoral pain syndrome: a randomized controlled clinical trial. J Orthop Sports Phys Ther. 2010;40(11):736-42.

25. Khayambashi K, Mohammadkhani Z, Ghaznavi K, Lyle MA, Powers CM. The effects of isolated hip abductor and external rotator muscle strengthening on pain, health status, and hip strength in females with patellofemoral pain: a randomized controlled trial. J Orthop Sports Phys Ther. 2012;42(1):22-9.

26. Mason M, Keays SL, Newcombe PA. The effect of taping, quadriceps strengthening and stretching prescribed separately or combined on patellofemoral pain. Physiother Res Int. 2011;16(2):109-19.

27. Rixe JA, Glick JE, Brady J, Olympia RP. A review of the management of patellofemoral pain syndrome. Phys Sportsmed. 2013;41(3):19-28.

28. Heintjes E, Berger MY, Bierma-Zeinstra SM, Bernsen RM, Verhaar JA, Koes BW. Exercise therapy for patellofemoral pain syndrome. Cochrane Database Syst Rev. 2003;(4):CD003472.

29. Cichanowski HR, Schmitt JS, Johnson RJ, Niemuth PE. Hip strength in collegiate female athletes with patellofemoral pain. Med Sci Spots Exerc. 2007;39(8):1227-32.

30. Robinson RL, Nee RJ. Analysis of hip strength in females seeking physical therapy treatment for unilateral patellofemoral pain syndrome. J Orthop Sports Phys Ther. 2007;37(5):232-8.

31. Lee TQ, Morris G, Csintalan RP. The influence of tibial and femoral rotation on patellofemoral contact area and pressure. J Orthop Sports Phys Ther. 2003;33(1):686-93. 
32. Cabral CMN, Monteiro-Pedro V. Recuperação funcional de indivíduos com disfunção femoropatelar por meio de exercícios em cadeia cinética fechada: revisão da literatura. Rev Bras Fisioter. 2003;7(1):1-8.

33. Meira EP, Brumitt J. Influence of the hip on patients with patellofemoral pain syndrome: a systematic review. Sports Health. 2011;3(5):455-65.

34. Powers CM. The influence of abnormal hip mechanics on knee injury: a biomechanical perspective. J Orthop Sports Phys Ther. 2010;40(2):42-51.

35. Harvie D, O'Leary T, Kumar S. A systematic review of randomized controlled trials on exercise parameters in the treatment of patellofemoral pain: what works? J Multidiscip Healthc. 2001;4:383-92.
36. Herrington L, Al-Sherhi A. A controlled trial of weight-bearing versus non-weightbearing exercises for patellofemoral pain. J Orthop Sports Phys Ther. 2007;37(4):155-60.

Received in 06/02/2015

Recebido em 02/06/2015

Approved in 06/07/2016

Aprovado em 07/06/2016 